\title{
Infraestruturas Migratórias Transnacionais: O Centro Islâmico de Recife na mediação de mobilidades 'sul'-'sul'
}

Anna Kurowicka

$\mathrm{O}$ artigo tem como ponto de partida a pesquisa em andamento que ainda está em sua fase inicial, realizada no Centro Islâmico da cidade de Recife. O Centro Islâmico, de uma forma paralela a seu papel como lugar de culto, situa-se como referência para os migrantes transnacionais 'Sul-Sul' na capital pernambucana. Participa do processo de mediação de mobilidade dos migrantes à cidade de Recife constituindo-se em um local de troca de informações, obtenção de orientações e contatos, etc. Infraestruturas migratórias são interconectadas a tecnologias, instituições e atores, que facilitam e condicionam a mobilidade. A proposta é repensar a importância do Centro Islâmico nas infraestruturas migratórias, como ponto convergente nesses processos de mobilidade. Observa-se também como a mediação da mobilidade resulta em um processo de politização das infraestruturas que a condicionam.

Migrações Sul-Sul, Migrações Transnacionais, Infraestruturas Migratórias, Centro Islâmico.

O presente artigo pretende colocar como ponto de partida a pesquisa em andamento realizada no Centro Islâmico da cidade de Recife, referente às migrações 'Sul-Sul' para a capital pernambucana. $\mathrm{O}$ estudo observa o papel do lugar de culto na configuração das infraestruturas migratórias - sistematicamente interligadas tecnologias, ins-

a Doutora em Antropologia Social (Universidade de Barcelona). Pesquisadora do Laboratório de Antropologia Visual (LAV-UFPE) e do Núcleo de Estudos e Pesquisa sobre Etnicidade (NEPE-UFPE).Email: annankania@yahoo.es. 
tituições e atores, que condicionam a mobilidade (Xiang \& Lindquist 2014). O Centro Islâmico é um local que contém um inédito - para os parâmetros próprios da cidade de Recife- trânsito de estrangeiros, praticamente todos os oriundos das regiões do 'Sul Global'. Não é raro encontrar ali estrangeiros de várias nacionalidades, tais como egípcios, libaneses, senegaleses, nigerianos, beninianos, palestinos, indianos, paquistaneses, entre outras mais possibilidades. Ao mesmo tempo, entre os reunidos pode-se presenciar pessoas com status social, econômico e/ou legal bem diferente, variando entre os refugiados, ou os imigrantes não documentados, e os profissionais de alto nível das importantes empresas instaladas em Pernambuco ${ }^{2}$. O Centro acolheu os estrangeiros como lugar de troca de informações e orientações, estabelecer amizades e contatos, intercambiar experiências e viver momentos da comunidade. O Centro Islâmico constitui-se em um espaço de mediação, um ponto convergente no fluxo transnacional, atribuindo um papel importante na materialização das migrações 'Sul-Sul' no âmbito da capital pernambucana.

As migrações 'Sul-Sul' são um fragmento de uma realidade maior caracterizada pela movimentação supranacional da capital e das pessoas que se deslocam entre as regiões do planeta, impulsionando mudanças nas sociedades que abrangem com sua atividade. A consolidação das novas economias no chamado 'Sul' mundial, junto com a diversificação das situações locais e com a cada vez mais complicada mobilidade em direção aos países do 'Norte', reforçou o surgimento das atuais infraestruturas migratórias entre as regiões do 'Sul'. Se observa que a partir do final da primeira década dos anos 2000, o Brasil reconfigurou sua posição no mapa das rotas migratórias 'Sul-Sul', constituindo-se como um país receptor de migrantes ${ }^{3}$. Essa situação teve a ver com a boa conjuntura econômica do momento, e também com uma série de facilidades legais e anúncios oficiais sobre a abertura do país para a recepção de imigrantes (Uebel 2017). Atualmente estamos observando o declive dessa situação: com a crise econômica em curso, a tendência é a diminuição do fluxo de imigrantes para o 
Brasil (Uebel 2017). Em paralelo, aumentam os discursos políticos contrários à chegada e à instalação de novos imigrantes ${ }^{4}$.

Dentro desse contexto sociopolítico e econômico vão se introduzindo as migrações 'Sul-Sul', que têm como seu ponto de referência o Centro Islâmico da cidade de Recife. Constatamos que as migrações se veem conectadas com e condicionadas por vários processos e dinâmicas de diversos campos; por exemplo, a movimentação do capital, os discursos políticos ou ideológicos existentes, as formas burocráticas e de controle impulsionadas pelos estados nacionais, diferentes tecnologias, como são as formas de transporte, de comunicação com as pessoas próximas na diáspora, de circulação da informação pelas redes sociais, entre outros. Daí, não é tanto "[...] o migrante quem migra, é a constelação feita pelos migrantes e os não-migrantes, pelos atores humanos e não-humanos que o fazem migrar" (Xiang \& Lindquist 2014:3). A agência dos migrantes no processo migratório só pode ser entendida em relação aos outros processos dos quais a migração faz parte, inserindose e criando - de acordo com a nossa perspectiva - as infraestruturas migratórias. O centro Islâmico de Recife é um elo importante no fluxo de pessoas 'Sul'-'Sul', movimentadas pelas distintas infraestruturas migratórias e abrangendo com a sua atividade a capital pernambucana.

\section{Centro Islâmico de Recife e as migrações 'sul'-'sul'}

O Centro Islâmico de Recife encontra-se numa antiga casa no bairro da Boa Vista, no centro histórico da cidade. O bairro da Boa Vista em Recife, junto aos outros bairros centrais, entrelaça no seu passado e no seu presente os distintos movimentos migratórios que por aí transitaram. O Centro Islâmico da Rua da Glória no 353 é praticamente pioneiro no sentido de cultivar a fé muçulmana de forma institucionalizada na cidade de Recife; foi fundado no ano de 1989 e passou posteriormente por um momento crítico, para voltar a abrir as portas no ano de 1997. O Centro Islâmico do Recife desde o seu começo teve uma vasta importância para a comunidade estrangeira na cidade precedente das migrações 'Sul-Sul'. "Todo muçulmano, quan- 
do chega em um novo lugar, deve procurar um centro ou uma mesquita para se reunir e realizar as práticas religiosas" - disse um dos líderes do Centro, Mamadou Toure. Essa realidade ajuda o Centro Islâmico a ser convertido de uma forma 'natural' em um local de encontro entre os diferentes migrantes 'Sul-Sul'.

O Centro tem três pessoas que atuam para seu funcionamento. Podemos identificar uma liderança, o imam Sheikh Mabrouk El Sawy: egípcio fundador e estudioso de teologia formado na Universidade de Al-Azhar, no Cairo, que conduz as cerimônias religiosas e as rezas. O conselheiro consultivo Alberto Bret, recifense conhecido como Rashid, é quem zela e administra o Centro. Por fim, o senegalês Mamadou Toure - presidente da Associação dos Senegaleses do Nordeste, que tem a sua sede no Centro Islâmico - ajuda na administração do Centro e fica na frente dos eventos religiosos na ausência do Sheikh Mabrouk El Sawy. Sem deter os números exatos, a pequena comunidade de fiéis do Centro Islâmico se compõe mais ou menos em sua metade de estrangeiros migrantes 'Sul-Sul', e metade brasileiros. Alberto Bret (Rashid) lembra que por volta do ano de 2015 a casa de culto tinha mais membros de outros países do que de brasileiros, sendo esses principalmente senegaleses que já deixaram, em grande número, a cidade de Recife. Naquela época, às sextas-feiras o Centro ficava sem espaço para receber tantas pessoas. Hoje em dia essa tendência diminuiu, mesmo com a participação dos estrangeiros no ambiente do Centro Islâmico ainda sendo bem visível.

O local do centro Islâmico situa-se numa antiga casa do bairro da Boa Vista, em Recife, que foi adaptada para poder cumprir sua função através de uma divisão e reorganização do espaço. Logo na entrada está situado um pequeno quarto que serve de despacho e é utilizado pelas pessoas que estão à frente da casa de culto: Sheik Mabrouk El Sawy, Alberto Bret Rashid e Mamadou Toure. O resto do lugar se compõe em uma única sala, ornada com os característicos tapetes e com os cartazes referidos a momentos do ano religioso nas paredes. Não há cadeiras, pois o costume pede sentar no chão durante as rezas e duran- 
te o tempo de permanência no templo em geral. Há algumas estantes perto das paredes, onde pode-se encontrar exemplares do Alcorão. A primeira parte dessa sala, contando a partir da entrada, pertence aos homens, e as mulheres e as crianças (quando acompanhadas da mãe) sentam na parte de trás. Na hora da reza, o imam ou o substituto dele conduz a oração na parte dianteira da sala. Depois da sala temos a cozinha, um elemento muito importante para as reuniões, já que cada encontro termina com uma refeição para todos. No caminho para o banheiro, no pequeno corredor, encontra-se uma torneira destinada a fazer a tradicional ablução das mãos e dos pés antes de entrar - descalço - na sala de reza.

A segunda maior religião do mundo, o Islã em suas distintas vertentes, está presente em praticamente todos os continentes, e a comunidade de fiéis do Islã forma quase um quarto da população mundial, de acordo com Pew Resarch Center 5 . No Brasil, a comunidade muçulmana se resume a 35.167 seguidores (representando 0,02\% das pessoas residentes no Brasil), segundo dados do censo demográfico de 2010 do Instituto Brasileiro de Geografia e Estatística (IBGE), sendo mais concentrada nas regiões Sul e Sudeste do país. Não existem dados exatos referidos ao número de muçulmanos em Recife, nem os que poderiam distinguir os fiéis do Islã de origem estrangeira. Mas podemos constatar que a busca pelos centros religiosos islâmicos sempre foi a opção dos migrantes muçulmanos que chegavam ao Brasil oriundos dos distintos países do mundo ao longo dos séculos (Castro \& Vilela 2019). Nesse sentido, o papel do Centro Islâmico recifense dá continuidade a uma tradição de acolhimento enraizada na prática de culto, e encontra-se numa posição paralela com as políticas contemporâneas e ações para a imigração promovidas pelo Estado ou pela sociedade civil.

\section{As infraestruturas migratórias transnacionais e o Centro Islâmico de Recife}

A partir do final dos anos 80 do século passado, dentro dos estudos das migrações surge um novo olhar que pretende desvincular 
as interpretações das realidades estudadas dos contextos estritamente nacionais. Começa com isso a crítica do chamado 'nacionalismo metodológico': conceito que reflete a ideia do estreitamento dos campos das análises sobre as migrações somente aos seus referentes nacionais. Essa mudança não surge como efeito de alguma mudança efetiva no próprio caráter das migrações, que há séculos já se relacionavam com os sistemas econômicos mundiais e influenciavam várias dinâmicas globais. Porém, na década de 90 o paradigma da migração transnacional tornou-se popular, em razão das discussões sobre a globalização (Appadurai 1996). No campo dos estudos das 'migrações transnacionais' poderiam ser mencionados os trabalhos de Green Basch, Glick Schiller \& Szanton Blanc (1994) ou Feldman-Bianco \& Glick Schiller (2011).

A principal mudança no olhar sobre as migrações que surge junto com o estabelecimento da visão transnacional é a de situar o próprio fenômeno migratório dentro de outros mecanismos do 'sistema capitalista globalizado’ (Feldman-Bianco 2018). Dessa maneira, não se descartou a importância da ação individual, o funcionamento dos migrantes em redes, ou por exemplo as desigualdades pós-coloniais entre as regiões. Mas a ênfase foi colocada numa compreensão conjunta da problemática das migrações e das análises do 'atual sistema político e econômico mundial'. Com isso, a circulação de pessoas começou a ser contemplada junto com a circulação do capital, mas também das ideias e dos símbolos que ajudam a recriar o sentido da globalização. O migrante viu-se convertido em objeto e sujeito dos processos hegemônicos que envolvem no mínimo dois estados nacionais, enfrentando na sua vida estruturas de poder desigual e discriminação numa experiência que atravessa as fronteiras do Estado (Feldman-Bianco 2018). A própria agência do migrante nesses processos está sendo redimensionada em função da sua participação nos diversos processos que estão em curso e que não dependem de forma direta somente do nosso ator, o migrante.

É justamente nesse ponto de reflexão, a partir da perspectiva transnacional, que os estudos sobre as migrações se encontram com a 
categoria de infraestrutura como conceito metodológico. As infraestruturas são partes invisíveis - tecnológicas, institucionais, humanas e não-humanas - dos sistemas, que garantem o seu funcionamento (Star 1999). São redes ou malhas construídas que facilitam o fluxo dos bens, pessoas, ideias ou poder; permite sua troca pelo espaço (Larkin 2013). Daí, a migração é condicionada pelas infraestruturas (Xiang \& Lindquist 2014), ou seja, pelas possibilidades tecnológicas de deslocamento, pelas formas de regulamentações burocráticas referentes à mobilidade, pelas formas clandestinas e oficiais de movimentação das pessoas entre países, etc. É um conglomerado de situações e agências que constroem o processo migratório, os próprios migrantes e os respectivos países de origem e de destino são só uma parte desse enredo de atores. As infraestruturas migratórias transnacionais permitem a mobilidade, inscrevendo-se dentro do contexto das atuais dinâmicas globais de movimentação dos bens, ideias e pessoas.

Entre os poucos trabalhos antropológicos sobre a problemática das migrações focados na categoria de infraestrutura, encontra-se o estudo de Xiang \& Lindquist sobre as migrações asiáticas (2014). Os autores estipulam nele cinco dimensões da infraestrutura de migração para fins analíticos: (1) a comercial (intermediários de recrutamento); (2) a reguladora (aparato estatal e procedimentos para documentação, licenciamento, treinamento ou outros fins); (3) a tecnológica (comunicação e transporte); (4) a humanitária (ONG e organizações internacionais); (5) a social (redes migratórias). $\mathrm{O}$ processo de migração se estabelece na interdependência entre as distintas dimensões da infraestrutura migratória, podendo variar a temporalidade dos elementos que o sustentam. Por último, Xiang \& Lindquist (2014) chamam atenção para o caráter de agência das infraestruturas que nem sempre é positivo, e que pode tanto facilitar quanto dificultar a mobilidade dos migrantes, dando a esse segundo caso o nome de 'involução das infraestruturas' (Xiang \& Lindquist 2014).

A partir da ótica de Xiang \& Lindquist, podemos enxergar a importância do Centro Islâmico em pelo menos três das dimensões das 
infraestruturas: reguladora, humanitária e social. A infraestrutura reguladora está estritamente ligada ao 'aparato de migração' (Feldman' 2011): são definidas como instituições díspares, políticas e como discursos que transformam a migração em objeto de políticas de Estado. É nessa etapa do processo migratório que são produzidas as diferentes categorias dos imigrantes, como os 'legais' e os 'ilegais', os 'documentados' e os 'não-documentados', o que posteriormente vai refletir no acesso aos direitos. Várias questões entram aqui em jogo, incluindo as relações diplomáticas entre os estados nacionais e as forças políticas dominantes em cada momento em distintos países, para a formulação das categorias dos migrantes que vão refletir depois na sua posição no novo país. O Centro Islâmico lida com a gestão dessas categorias, orientando e ajudando nos processos burocráticos dos imigrantes reunidos na casa de culto.

A infraestrutura reguladora, ao 'produzir o imigrante' como uma categoria discursiva, política e legislativa, se conecta com uma outra infraestrutura importante para a mediação da migração que é a infraestrutura humanitária. A figura do imigrante representa um tipo específico de cidadão, com os direitos reduzidos ou só com os direitos humanos básicos (pode acontecer no caso dos imigrantes 'indocumentados' ou 'ilegais', por exemplo). Como tal, o imigrante vai precisar de 'acolhimento', como um pedido humanitário, e 'acolher' vai ser a responsabilidade tanto do Estado, quanto dos outros atores e instituições que não pertencem ao próprio grupo de imigrantes. Poderíamos falar aqui de uma 'indústria' do 'acolhimento', incluindo as mídias, as ONG, igrejas, sociedade civil, à parte das políticas do Estado. São importantes os circuitos de financiamento, redes internacionais de defesa dos direitos, circulação das normas dos direitos humanos e imagens ou discursos de sofrimento. O Centro Islâmico inscreve-se no mapa da infraestrutura humanitária e no contexto das migrações 'Sul-Sul' para a cidade de Recife, como mediação de acesso aos direitos ou às formas de solidariedade que se articulam a partir do local. Um bom exemplo poderia ser a arrecadação de 10 reais todos 
os meses de cada um dos senegaleses para criar um fundo emergencial que pode ser acionado no caso de algum imprevisto (morte, doença, etc.), ou o papel de Mamadou Toure como conselheiro municipal dos direitos humanos.

O Centro Islâmico de Recife pode ser pensado também como uma infraestrutura social, ao ajudar a articular a mobilidade entre os novos e os velhos imigrantes. Referência para o primeiro contato dos recém-chegados, o Centro Islâmico não só ampara no acolhimento, mas também ajuda na busca do primeiro emprego, dá assistência nos problemas com a língua portuguesa, orienta nas questões legais ou auxilia na resolução dos trâmites burocráticos. Por outro lado, o Centro Islâmico mantém vínculos com alguns dos países de origem dos migrantes, convidando as importantes personagens do âmbito religioso para a cidade de Recife, por exemplo. Através da prática comum da mesma concessão, o Centro Islâmico recria os laços de proximidade e solidariedade entre os membros, apoiando dessa forma o surgimento de várias redes de ajuda mútua. Dessa forma, o Centro realiza o seu papel tradicional para as migrações muçulmanas (Castro \& Vilela 2019), constituindo-se ao mesmo tempo no contexto moderno das mobilidades transnacionais.

\section{Centro Islâmico: entre o político e o poético das infraestruturas}

Repensando o papel do Centro Islâmico da cidade na mediação de mobilidade, vemos que uma boa parte da sua agência no processo migratório vem no sentido de preencher o vazio das políticas públicas e de ações do próprio Estado. Poderíamos pensar aqui no conceito trabalhado por Xiang \& Lindquist - involução das infraestruturas migratórias - como a descrição dessa situação (Xiang \& Lindquist 2014). A involução das infraestruturas se dá quando a interação entre as diferentes dimensões da infraestrutura migratória torna-a autoperpetuadora [...], impedindo ao invés de aumentar a capacidade migratória das pessoas" (Xiang \& Lindquist 2014:1). Como vai ser demostrado 
na continuação, no que depender do Estado, as migrações 'Sul-Sul' para a cidade serão um fenômeno praticamente invisível - ao não se tratar da mobilidade dos refugiados venezuelanos. Nesse contexto, está nas mãos dos próprios migrantes buscar formas de articulação que visem à adesão à vida na cidade, sendo a atividade do Centro Islâmico uma das propostas. $\mathrm{O}$ Estado nesse contexto mostra-se como o ator que vai reproduzir e sustentar as situações de exclusão e marginalização, fazendo involuir as infraestruturas migratórias presentes na mobilidade 'Sul-Sul' para a cidade.

Daí as infraestruturas - tanto migratórias como as outras - são profundamente políticas, no sentido que o acesso a elas depende dos diferentes pertencimentos aos grupos sociais com as suas distintas posições. As infraestruturas são territórios da mediação do poder, já que vemos que o alcance a elas não é igualitário. Como exemplo, observamos que na mesma cidade há bairros onde o transporte público chega perto de todas as residências, enquanto em outros, as pessoas têm que fazer uma boa parte dos seus deslocamentos andando. Ou que em um dos bairros o saneamento básico e o abastecimento de água funcionam bem, enquanto no bairro vizinho o esgoto está a céu aberto e há água apenas de três em três dias. Essas diferenças vão indicar claramente uma desigual preocupação do poder público com as duas comunidades, que têm como efeito prático uma desigualdade estrutural entre os bairros vizinhos. Se ainda conseguirmos afirmar que em um dos dois bairros a maioria das pessoas se identifica a partir de um fator étnico ou racial diferente que no outro, provavelmente estamos a observar - através dessas diferenças infraestruturais - a existência de racismo institucional naquela cidade. A partir dessa perspectiva, Anand junto com Gupta e Appel admitem, repensando as infraestruturas como uma categoria antropológica, que é importante saber "quais são as comunidades que vão precisar lutar pelo acesso às infraestruturas necessárias para a sua reprodução física e social?" (Anand, Gupta \& Appel 2018:11). Essa provavelmente vai ser a situação de uma boa parte dos migrantes 'Sul-Sul' reunidos no Centro Islâmico de Recife, 
lembrando também que não de todos, já que o status socioeconômico dos membros migrantes do Centro Islâmico é bem variado.

Olhando, porém, para o próprio local do Centro Islâmico, vemos que ele se encontra numa casa histórica em bastante mal estado de conservação e que precisaria de uma revitalização profunda, situando-se num bairro onde a maioria dos lugares vizinhos está na mesma condição. Não há sinais da preocupação das autoridades com a preservação ou com o tombamento dessa rica, em história, parte da cidade, e também as ruas estão sujas, mal iluminadas e cheias de buracos. O próprio local onde funciona o Centro não tem uma boa ventilação, correspondente ao clima tropical. É o lugar de encontro de muitas pessoas, sendo também constantes as faltas no abastecimento de água. Essas falhas infraestruturais referentes ao espaço físico do Centro são reforçadas pelo total desinteresse do Estado pelo local, sendo ele praticamente inexistente para as políticas públicas. Não há nenhuma conexão direta entre o funcionamento do Centro Islâmico e o poder institucionalizado, não há formas de apoio ou projetos que visariam a uma adequada preparação dos imigrantes para a vida na cidade, ou um melhor aproveitamento dos conhecimentos profissionais deles.

Mamadou Toure, do Centro Islâmico de Recife - que é também conselheiro municipal de direitos humanos - em uma das conversas nos esclareceu sobre as políticas para a imigração em Recife. $\mathrm{O}$ senegalês evidenciou que as promessas são muitas, mas nunca chegam a ser realizadas, sendo os estrangeiros deixados nas mãos deles mesmos. Pensando na comunidade senegalesa, o Centro retoma em uma parte a função organizativa e de acolhimento dos imigrantes, por meio de várias ações. Os laços do líder senegalês com as instâncias administrativas facilitam os trâmites burocráticos da legalização de residência - principalmente como refugiados - e alcançam o contato com outras organizações da sociedade civil que amparam os imigrantes. Nas conversas informais com as mulheres estrangeiras do Centro Islâmico, ficou evidente a necessidade do curso de língua portuguesa, um outro 
pedido que há anos espera para ser atendido pelo poder público. Mas até agora não conseguiu ser realizado.

A comparação com o caso dos refugiados venezuelanos que chegaram na cidade nos anos 2018-2019 pode trazer uma perspectiva melhor sobre a realidade. Tratando dos venezuelanos, a situação do tronco parecido - a vinda dos migrantes 'Sul-Sul' - foi aqui encarada de forma bem diferente. Foi engajada a participação do governo federal e do Estado do Pernambuco (projeto de 'interiorização'), Caritas brasileira e Caritas suíça, com o financiamento estadunidense. Só para o traslado dos 102 imigrantes, desde a fronteira com a Venezuela em Roraima, no dia 17 de dezembro de 2018, foi disponibilizada a Base Aérea de Recife e um comboio de 22 veículos oficiais do exército, incluindo ambulâncias. A acolhida dos recém-chegados foi articulada dentro do Programa $\mathrm{Pana}^{6}$, proporcionando acesso à moradia com aluguel subsidiado, acompanhamento psicossocial, oportunidade de qualificação profissional e atendimento jurídico. Para complementar as ações, os imigrantes em situação de 'vulnerabilidade social' tiveram acesso a itens de primeira necessidade como alimentos, roupas e kits de higiene pessoal. A Casa dos Direitos foi criada na Universidade Católica do Recife justamente em função de atender essas demandas dos imigrantes venezuelanos, mesmo que teoricamente o objetivo seja dar atenção a qualquer pessoa em situação migratória? .

Daí, cabe observar que as infraestruturas são políticas, mas elas também são 'poéticas': visibilizam desejos, conflitos e dilemas de uma sociedade (Larkin 2013). As infraestruturas, mas também os projetos ou as promessas das infraestruturas, revelam o leque de ideias das quais é construída a realidade no contexto de um grupo ou de um lugar concreto. Projetar as infraestruturas é dar forma às relações sociais, observar as infraestruturas é entender as relações que estão nelas cimentadas. A grande diferenciação entre a construção das infraestruturas migratórias no caso dos refugiados venezuelanos e dos migrantes 'Sul-Sul' reunidos no Centro Islâmico evidencia as opções políticas por trás delas. A ausência do Estado no segundo dos casos, 
em contraste com um visível interesse em auxiliar e dar uma boa visibilidade à chegada dos venezuelanos, alinha-se ideologicamente com a postura do governo brasileiro em referência ao Estado venezuelano. A exclusividade na forma de acolhimento desses diferentes migrantes procedentes do 'Sul' global mostra-se através das facilidades e das dificuldades, criadas ou perpetuadas, desde a plena articulação das instituições para apoiar a chegada dos imigrantes até uma praticamente total omissão das suas demandas, com os orçamentos e planejamentos que nunca saem do papel.

\section{Quando as pessoas são parte das infraestruturas}

As infraestruturas migratórias se sobrepõem e se introduzem nas diferentes 'malhas' e 'redes' que estruturam o 'sistema global capitalista' (Feldman-Bianco 2018), começando, assim, a formar parte dele. Com isso, as infraestruturas migratórias atualizam-se constantemente, entrelaçando-se com outras infraestruturas já existentes e inserindo-se em vários contextos não puramente migratórios. Um exemplo disso poderia ser o comércio internacional e a circulação dos bens, junto com o fluxo dos altos especialistas, mas também dos vendedores ambulantes ao redor do mundo. Com tudo isso os migrantes formam parte de uma realidade transnacional que não se reduz somente em movimentação das pessoas. A mobilidade dos migrantes vai ser tão importante para recriar a nossa atualidade do fluxo acelerado das ideias, símbolos ou capital, quanto a realidade da existência desse trânsito vai condicionar e impulsionar as migrações. E a conjunta articulação entre os distintos elementos e sujeitos que estão em movimento vai se organizar de acordo com as infraestruturas, as existentes e as novas que terão que ir surgindo para satisfazer essa demanda de mobilidade.

O exemplo de comércio informal das ruas de Recife e o papel do Centro Islâmico visualizam como pode-se materializar a junção das infraestruturas migratórias com as outras. Devemos pensar nesse caso em 'pessoas como infraestruturas' - 'people as infrastructure' - que é a noção introduzida por Simone no seu trabalho sobre a cidade de Jo- 
anesburgo (Simone 2004). Simone argumenta que há contextos onde o uso dos espaços da cidade por alguns grupos que a habitam se dá não tanto em função de uma rígida predestinação das infraestruturas, mas da constante flexibilidade e improvisação em assinar os usos e os significados a elas (Simone 2004). Nesse sentido, o olhar para a agência e a criatividade humana é indissociável da observação das infraestruturas, cujas finalidades nunca se veem acabadas antes que a ação dos atores esteja terminada. No contexto da tradição muçulmana - que abre o espaço da casa de culto para acolher as outras necessidades 'não religiosas' das pessoas - há espaço para espontaneidade no constante reinventar do funcionamento desse local. $\mathrm{O}$ acolhimento ao migrante tem uma trajetória própria dentro dos centros islâmicos do Brasil (Castro \& Vilela 2019), mas isso não contradiz também a realidade da importância de uma superfluidade na hora de se consolidar as infraestruturas com as ações humanas concretas e momentâneas. Mais ainda, o funcionamento do Centro Islâmico no contexto migratório só pode ser entendido em conexão com as pessoas que o constroem e com as práticas e atividades que se dão a partir do lugar.

Nesse contexto poderíamos pensar no exemplo da figura do Mamadou Toure dentro do Centro Islâmico e como através das ações dessa pessoa está se inserindo um contingente de imigrantes africanos na cidade de Recife. Mamadou Toure ocupa cargos institucionais referentes à presença dos imigrantes em Recife - como o já mencionado de conselheiro dos direitos humanos -, e de chefe da Associação dos Senegaleses do Nordeste, sendo ao mesmo tempo uma figura importante para a vida religiosa do Centro. Já na sua vida profissional, Mamadou é um grande comerciante que percorreu toda a América do Sul em busca de materiais de diferente natureza para serem comercializados. Atualmente, Mamadou Toure tem uma lojinha própria dentro da Feira de Artesanato de Pernambuco, na Av. Alfredo Lisboa, em Recife, onde já chegou a trabalhar com produtos vindos da Bolívia, do Paraguai e da Índia. O chefe da Associação Senegalesa abastecia antes os vendedores ambulantes senegaleses que trabalhavam nas praias da 
Argentina, nas ruas de São Paulo e em Salvador, na Bahia. Hoje em dia a figura dele é muito importante para a articulação da imigração africana em vários níveis, tanto pelo seu papel no Centro Islâmico e nas instâncias administrativas da cidade, quanto introduzindo vários dos africanos nas redes de comércio informal de Recife.

A partir do Centro Islâmico, mas com a importante participação do Mamadou Toure e da criatividade comercial dos próprios imigrantes, vai se concretizando a infraestrutura migratória que ao mesmo tempo faz parte de uma outra infraestrutura que é a de fluxo transnacional dos bens. Com isso os africanos, que se articulam como vendedores ambulantes dos produtos chineses nas ruas de Recife, fazem parte de uma forma plena dessa outra tão caraterística, para a época atual, circulação. As pessoas como infraestruturas - migratórias e comerciais - vão mediando com a constante inventividade a sua aderência às dinâmicas e realidades da urbe. O Centro Islâmico como local físico ou como instituição figura nesse contexto como ponto de conexão e aglutinação na articulação dessas pessoas como infraestruturas.

\section{Conclusões}

O Centro Islâmico da cidade de Recife é um ponto convergente de várias infraestruturas migratórias transnacionais, que condicionam a mobilidade 'Sul'-'Sul' para a capital de Pernambuco. Partindo do seu papel principal como lugar de culto, o local junta as tradições próprias dos centros islâmicos no Brasil em auxiliar na mobilidade das pessoas muçulmanas com as demandas atuais de mobilidade, surgidas no contexto do fluxo transnacional de pessoas, bens e ideias num mundo globalizado. Funciona como um elo que reforça, constrói e/ ou se inscreve em distintas constelações de situações, dinâmicas, tecnologias, processo burocráticos, etc., que condicionam a mobilidade. Com isso, o Centro Islâmico faz parte e dá continuidade às diferentes infraestruturas que fazem a migração acontecer. O Centro Islâmico é um local físico, é uma instituição, são as pessoas que o constroem e 
frequentam; são as ações por ele impulsadas ou mediadas; é um fragmento localizado de uma peculiar tradição muçulmana da mediação da mobilidade.

A categoria de infraestrutura como ferramenta metodológica para pensar o estudo sobre o Centro Islâmico e as migrações 'Sul-Sul' para a cidade possibilita uma visão abrangente e inclusiva dos elementos, agências e dinâmicas das quais constitui-se o processo de mobilidade. Esses podem ser tanto humanos como não-humanos, físicos como imateriais, visíveis e invisíveis: não há preferências na hora de definir do que se compõe uma infraestrutura. Nesse sentido a noção de infraestrutura migratória difere bastante, por exemplo, da ideia das redes migratórias, ao incluir atores humanos e não-humanos como as possíveis agências. Ao mesmo tempo, o conceito de infraestrutura - em contraste com o de rede migratória - devolve o caráter complexo e multidirecional da mobilidade, que envolve não só as pessoas, mas também os bens ou as ideias. Com isso, a infraestrutura como categoria metodológica permite desenhar trabalhos nos contextos dos debates contemporâneos, tais como as discussões sobre as migrações transnacionais ou sobre a globalização.

As infraestruturas migratórias facilitam, mas também dificultam a mobilidade, sendo em ambos os casos importantes definidores das formas de como a migração está se materializando: os acordos diplomáticos entre os países, os processos burocráticos referidos a direito de residência, as políticas públicas ou a falta destas. Vários fatores podem influir na perpetuação do carácter discriminatório e excludente das infraestruturas migratórias - na involução das infraestruturas (Xiang \& Lindquist 2014). No caso do Centro Islâmico, observamos que o Estado agência uma importante involução das infraestruturas responsáveis pelo fluxo migratório 'Sul-Sul'. Isso acontece principalmente pela invisibilização do próprio fenômeno migratório presente e de omissão em auxiliá-lo com as decisões ou ações políticas concretas. O papel do Centro Islâmico é em boa parte inverter essa situação e criar as condições favoráveis à realização do projeto migratório pelos 
migrantes 'Sul-Sul' reunidos na casa de culto. Cabe a afirmação de que nem todos os migrantes 'Sul-Sul' do Centro precisam de auxílio no sentido estrito de 'acolhimento' no processo migratório, e essa realidade refere-se só a uma parte deles. Vemos ao mesmo tempo que a involução das infraestruturas merece uma leitura profundamente política, que no caso estudado pode ser feita através da comparação entre a situação dos migrantes 'Sul-Sul' reunidos no Centro Islâmico e a dos refugiados venezuelanos.

As infraestruturas migratórias articulam-se de uma forma conjunta com as outras infraestruturas que não têm caráter estritamente migratório. $\mathrm{O}$ caso dos migrantes senegaleses é um exemplo de como a infraestrutura migratória introduziu-se na infraestrutura de comércio informal da cidade e de circulação transnacional dos bens. Os senegaleses ganharam uma boa visibilidade nas ruas da urbe justamente graças a sua atividade comercial como revendedores dos complementos, óculos ou relógios chineses. A figura do Mamadou Toure do Centro Islâmico foi bem significante para a instalação dessa atividade dos africanos; orientando com sua experiência como comerciante, mas também ajudando com os processos de residência - imprescindíveis para permanecer na cidade - e representando os interesses do coletivo através da Associação Senegalesa do Nordeste, sediada no Centro Islâmico. A ação conjunta articulada entre os migrantes senegaleses e o líder Mamadou Toure resultou na instalação de um tipo de comércio dominado por esse grupo, surgindo uma infraestrutura migratória e comercial comum.

agenciamento da infraestrutura por meio da pessoa pode ser pensado no sentido das situações onde as infraestruturas só vão ser entendidas quando conectadas com a ação das pessoas. As pessoas como infraestruturas (Simone 2004) aparecem lá onde a criatividade humana faz um constante reinventar das infraestruturas. A junção da infraestrutura comercial com a estrutura migratória, como no caso do comércio informal dos senegaleses reunidos no Centro Islâmico, começa a ser concebida quando interligada com a noção de pessoas 
como infraestrutura. O Centro Islâmico de Recife recebe um variado fluxo dos migrantes 'Sul-Sul', constituindo-se em um elo na infraestrutura migratória. Participa da mediação da mobilidade através das ações que surgem da tradição, mas também da espontaneidade e da criatividade como formas de lidar com os desafios de adesão às outras infraestruturas, ou para superar os desafios da involução das infraestruturas. É por isso que o Centro Islâmico - como parte da infraestrutura migratória - se vê como um projeto nunca acabado, mas sempre aberto às necessidades de se adaptar às circunstâancias de mobilidade de cada momento.

\section{Notas:}

1 A categoria 'Sul Global' é amplamente mobilizada, em particular nos discursos políticos contemporâneos, para classificar os países do mundo cuja economia é influenciada hegemonicamente por um hipotético 'Norte Global'. O 'Sul Global', que é uma categoria em particular revitalizada da consolidação de redes econômicas entre os países do BRICS, é uma estratégia para superar as dicotomias entre países desenvolvidos' e 'subdesenvolvidos', que amplamente influenciou a gestão da circulação de pessoas.

2 Um exemplo poderia ser a matéria do Jornal de Comércio, 'Muçulmanos do Recife condenam ataques terroristas', fonte: https://jconline.ne10.uol.com.br/canal/ mundo/internacional/noticia/2015/11/21/muculmanos-do-recife-condenam-ataques-terroristas-209092.php.

3 Consultar nesse sentido: https://www.justica.gov.br/news/collective-nitf-content-1566502830.29.

4 O exemplo da postura contrária à entrada e permanência dos imigrantes no Brasil pode ser a polêmica Portaria 666 do ministro de Justiça e Segurança Pública Sérgio Moro. Mais sobre o assunto: https://jamilchade.blogosfera.uol.com. br/2019/09/18/portaria-de-moro-sobre-deportacao-e-denunciada-na-onu/?fbcli$\mathrm{d}=I w A R 3 j R s 0 e 6 r$ RsvScrWUGyOA1TSNC86ib-F_Coi1ILZj_iAEMhRwuz109pAro.

5 Fonte: https://www.pewresearch.org/fact-tank/2017/08/09/muslims-and-islam-key-findings-in-the-u-s-and-around-the-world/.

6 Programa Pana é um programa especial para o acolhimento dos imigrantes e refugiados, articulado dentro da Caritas brasileira.

7 Fonte: site do Caritas brasileira, www.caritas.br. 


\section{Referências:}

ANAND, N., GUPTA, A. \& APPEL, H. 2018. "Introduction: Temporality, Politics, and the Promise of Infrastructure”, In ANAND, N., GUPTA, A. \& APPEL, H. (eds.): The promise of infraestructure: a School for Advanced Research Advanced Seminar, pp. 3-40. Durham\&London: Duke University Press.

APPADURAI, A. 1996. Modernity at Large: Cultural Dimensions of Globalization. Minneapolis: University of Minnesota Press.

ARANGO, J. 2000. "Explaining Migration: a critical view”, International Social Science Journal, 52(165):283-296. . 2003. "La Explicación teórica de las migraciones: Luz y sombra Migración y Desarrollo”. Red Internacional de Migración y Desarrollo, 1:1-30.

ASFORA, J. S. 2002. Palestinos A saga de seus descendentes. Olinda: Ed. Primeira Edição.

CASTRO, C. M. \& VILELA, E. M. 2019. 'Muçulmanos no Brasil: uma análise socioeconômica e demográfica a partir do Censo', Religião e Sociedade, 39(1):170-197.

FELDMAN, G. 2011. The Migration Apparatus: Security, Labor, and Policymaking in the European Union. Stanford: Stanford University Press.

FELDMAN-BIANCO, B. \& GLICK SCHILLER, N. 2011. "Una conversación sobre transformaciones de la sociedad, migración transnacional y trayectorias de vida”. Crítica y Emancipación, 3(5):9-42.

FELDMAN-BIANCO, B. 2018. "Anthropology and ethnography: the transnational perspective on migration and beyond”. Etnográfica, 22(1):195215.

GREEN BASCH, L., GLICK SCHILLER, N. \& SZANTON BLANC, C. 1994. Nations unbound: transnational projects, postcolonial predicaments, and deterritorialized nation-states. London: Routledge.

LARKIN, B. 2013. "The Politics and Poetics of Infrastructure". Annual Review of Anthropology, 42:327-343.

PIORE, M. J. 1979. Birds of Passage: Migrant Labor in Industrial Societies. Cambridge: Cambridge University Press.

ROCHA PINTO, P. 2010. Árabes no Rio de Janeiro: Uma identidade plural. Rio de Janeiro: Editora Cidade Viva.

SIMONE, A. 2004, "People as Infrastructure: Intersecting Fragments in Johannesburg”. Public Culture, 16(3):407-429.

STAR, S. L. 1999. "The Ethnography of Infrastructure”. American Behavioral Scientist, 43(3):377-391.

STARK, O. \& TAYLOR, J. E. 1989 "Relative Deprivation and International Migration”. Demography, 26(1):1-14. 
UEBEL, R. 2017. Análise da política externa migratória brasileira para a América Latina e África dos governos Lula da Silva e Dilma Rousseff. Trabalho apresentado no "6o Encontro Nacional da Associação Brasileira de Relações Internacionais”, Pontifícia Universidade Católica de Minas Gerais. Belo Horizonte-MG.

WALLERSTEIN, I. 1974. The Modern World-System. Capitalist Agriculture and the Origins of the European World-Economy in the Sixteenth Century. New York: Academic Press.

VAINASENCHER, S. 2009. Boa Vista (Bairro Recife).

(http://basilio.fundaj.gov.br/pesquisaescolar/index.phpoption=com content\& view $=$ article\& id $=470 \&$ Itemid $=1$; accesso em 01/05/2020).

XIANG, B. \& LINDQUIST, J. 2014. "Migration Infrastructure". International Migration Review, 48(S1):122-148.

\begin{abstract}
The article has as a starting point the research in progress and which is still in its initial phase, carried out at the Islamic Center of the city of Recife. The Islamic Center, in parallel with its role as a place of worship, stands as a reference for transnational 'South-South' migrants in the capital of Pernambuco. Participates in the mobility mediation process of migrants to the city of Recife, constituting a place for exchanging information, guidance, establishing contacts, etc. Migratory infrastructures are interconnected technologies, institutions and actors, which facilitate and condition mobility. The proposal is to rethink the importance of the Islamic Center in migratory infrastructure, as a convergent point in these mobility processes. It is also observed how the mediation of mobility results in a process of politicization of the infrastructures that condition it.
\end{abstract}

Keywords: South-South migration, Transnational migrations, Migratory infrastructures, Islamic Center.

Recebido em outubro de 2020. Aprovado em dezembro de 2020. 